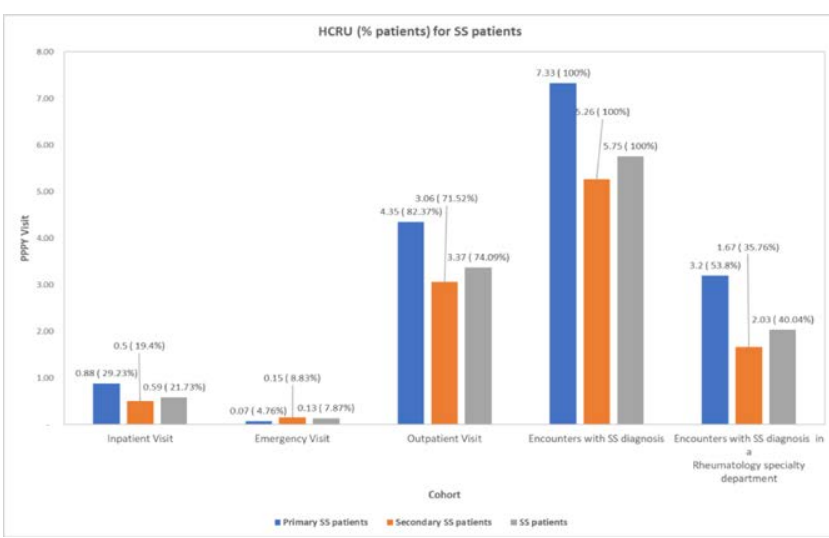

Figure 2. Treatment Sequencing for pSS and sSS PtsNote:Discontinued: pts who discontinued and didn't advance to any therapy; same treatment: pts continued on index treatment till we have information.

describe pts' demographic and clinical characteristics, and medications use in the baseline and follow up.

Results: Study cohort included 9,108 SS pts of which $76.5 \%$ had sSS diagnosis on index date. Majority of SS pts were women, Caucasian, with mean age of 58.3 yrs, and from western states in the US (Table 1). Endocrine conditions including hypo- and hyperthyroidism, and diabetes was the most common (45.5\%) comorbidity at baseline, followed by rheumatologic disorders (25.6\%) and neurological conditions (22.2\%). Among patients with treatment information (4088, 44.88\%), $42.95 \%$ were using symptomatic treatments for dry eye and mouth at baseline (Table 1). In the follow-up, SS pts had average 5.8 healthcare visits per patient per year (PPPY), including 0.6 inpatient and 3.4 outpatient visit respectively. About $40 \%$ of the SS pts (53.8\% pSS and $35.8 \%$ sSS) were diagnosed by rheumatologists. Majority of the SS pts initiated treatment with cDMARDs (82\%) and remained on the same treatment during 1 year follow-up (Fig 2).

Conclusion: Observation of higher comorbidities suggests substantial burden of SS pts on healthcare system, with majority of pts being diagnosed outside of rheumatology offices.

Acknowledgments: : We acknowledge the contributions of Manasi Suryavanshi towards drafting and reviewing the abstract.

Disclosure of Interests: Philip J Mease Grant/research support from: Abbott, Amgen, Biogen Idec, BMS, Celgene Corporation, Eli Lilly, Novartis, Pfizer, Sun Pharmaceutical, UCB - grant/research support, Consultant of: Abbott, Amgen, Biogen Idec, BMS, Celgene Corporation, Eli Lilly, Novartis, Pfizer, Sun Pharmaceutical, UCB - consultant, Speakers bureau: Abbott, Amgen, Biogen Idec, BMS, Eli Lilly, Genentech, Janssen, Pfizer, UCB - speakers bureau, Joe Zhuo Shareholder of: Bristol-Myers Squibb, Employee of: Bristol-Myers Squibb, Roshanthi Weerasinghe Grant/research support from:., Qian Xia Shareholder of: I own shares of Bristol-Myers Squibb Company, Employee of: I am a paid employee of Bristol-Myers Squibb Company, Chidananda Samal Consultant of: I work as a consultant for Bristol-Myers Squibb Company, Niyati Sharma Consultant of: I work as a consultant for Bristol-Myers Squibb Company

DOI: 10.1136/annrheumdis-2020-eular.4187

\begin{tabular}{|l|l|}
\hline SAT0220 & BIOLOGICAL PREDICTORS OF ECHOGRAPHIC \\
SALIVARY GLAND INVOLVEMENT SEVERITY IN \\
PATIENTS WITH SJÖGREN'S SYNDROME
\end{tabular}

A. Mihai ${ }^{1}$, D. Mardale ${ }^{1}$, D. Opris-Belinski ${ }^{2}$, R. Ionescu' ${ }^{2}$ C. Jurcut ${ }^{1} .{ }^{1}$ "Dr. Carol Davila"Central Emergency University Military Hospital, Bucharest, Romania; 2 "Sf. Maria” Clinical Hospital, "Carol Davila” University of Medicine and Pharmacy, Bucharest, Romania

Background: Echographic evaluation of salivary gland increasingly became a routine imaging modality in patients with Sjogren's syndrome (SS). However, predictive parameters associated with the severity of echographic features are still incomplete evaluated.

Objectives: The aim of this study was to evaluate the predictors for severe echographic involvement in patients with SS followed in a tertiary center.

Methods: We included 63 patients with SS (mean age: $52.3 \pm 11.9 ; 59$ female). The complete laboratory workup, clinical manifestations and treatment were reviewed and the EULAR Sjögren's syndrome disease activity index (ESSDAI) was calculated for each patients. We performed the standard echographic evaluation of salivary gland in all patients and used a 4 grade system for severity staging.

Results: The distribution of echographic grade was: no any echographic features -4 pts $(6.3 \%)$; grade $1-24$ pts $(38.1 \%)$; grade $2-20$ pts $(31.7 \%)$; grade 3 - 10 pts (15.9\%); grade $4-5$ pts (7.9\%). The ESSDAI and the hydroxichloroquine use were similar in these subgroups. We didn't find differences regarding CRP and fibrinogen and echographic features. The age of the patients, the anti-SSA and anti-SSB, ESR, total protein, IgA, IgG and rheumatoid factor levels were significantly higher and lymphocyte count was lower in patients with echographic severity above grade 2 when compared with patients with no or mild echographic features. However, using ANOVA test and post-hoc analysis, the only parameters associated with the severity of echographic features were high ESR (53 vs 17 in grade 4 vs $1, p=0.02$ ), $\operatorname{lgA}$ (363 vs 190 in grade 4 vs $1, p=0.004)$ and $\lg$ (1985 vs $1191 \mathrm{U} / \mathrm{l}$ in grade 4 vs $1, p=0.001$ ) levels.

Conclusion: Parameters linked to polyclonal hypergammaglobulinemia (IgA and IgG levels; and ESR) seem to be linked to the severity of echographic appearance of salivary gland in patients with SS. Further studies are needed in order to better characterize this link.

Disclosure of Interests: Ancuta MIHAI: None declared, DENISE MARDALE None declared, Daniela Opris-Belinski Speakers bureau: as declared, Ruxandra lonescu Consultant of: Consulting fees from Abbvie, Eli-Lilly, Novartis, Pfizer, Roche, Sandoz, Speakers bureau: Consulting and speaker fees from Abbvie, EliLilly, Novartis, Pfizer, Roche, Sandoz, Ciprian Jurcut: None declared DOI: 10.1136/annrheumdis-2020-eular.2292

\begin{tabular}{|l|l|}
\hline SAT0221 & FACTORS AFFECTING MORTALITY OF SYSTEMIC \\
& LUPUS ERYTHEMATOSUS PATIENTS IN SPAIN IN \\
& THE 21ST CENTURY: DATA FROM THE RELESSER \\
& REGISTRY
\end{tabular}

C. Moriano $^{1}$, J. Calvo ${ }^{2}$, I. Rua-Figueroa ${ }^{3}$, E. Diez Alvarez ${ }^{1}$, C. Bermúdez ${ }^{4}$ F. J. López-Longo ${ }^{5}$, M. Galindo-Izquierdo ${ }^{6}$, A. Olive ${ }^{7}$, E. Tomero Muriel ${ }^{8}$, A. Fernandez-Nebro ${ }^{9}$, M. Freire González ${ }^{10}$, O. Fernández-Berrizbeitia ${ }^{11}$ A. Pérez Gómez ${ }^{12}$, E. Uriarte Isacelaya ${ }^{13}$, C. Marras Fernandez $\mathrm{Cid}^{14}, \mathrm{C}$. A. Montilla-Morales ${ }^{15}$, G. Santos Soler ${ }^{16}$, R. Blanco ${ }^{17}$, M. Rodíguez-Gómez ${ }^{18}$, P. Vela-Casasempere ${ }^{19}$, A. Boteanu ${ }^{20}$, J. Narváez $^{21}$, V. Martinez Taboada ${ }^{17}$, B. Hernández-Cruz ${ }^{22}$, J. L. Andreu ${ }^{23}$, J. A. Hernandez Beriain ${ }^{24}$, L. Expósito ${ }^{25}$, R. Menor-Almagro ${ }^{26}$, M. Ibañez Barceló ${ }^{27}$, I. Castellví ${ }^{28}$, C. Galisteo ${ }^{29}$, E. Raya ${ }^{30}$, V. Quevedo Vila ${ }^{31}$, T. Vazquez Rodriguez ${ }^{32}$, J. Ibañez ${ }^{33}$, J. M. Pego-Reigosa ${ }^{34}$. ${ }^{1}$ H León, León, Spain; ${ }^{2}$ H Araba, Vitoria, Spain; ${ }^{3}$ H Negrín, Las Palmas Gran Canaria, Spain; ${ }^{4}$ Research Unit Bioaraba, Vitoria, Spain; ${ }^{5} \mathrm{H}$ Gregorio Marañón, Madrid, Spain; ${ }^{6} \mathrm{H} 12$ Octubre, Madrid, Spain; ${ }^{7} \mathrm{H}$ German Trias i Pujol, Badalona, Spain; ${ }^{8} \mathrm{H}$ La Princesa, Madrid, Spain; ${ }^{9} \mathrm{H}$ Carlos Haya, Málaga, Spain; ${ }^{10} \mathrm{H}$ Juan Canalejo, A Coruña, Spain; ${ }^{11} \mathrm{H}$ Basurto, Bilbao, Spain; ${ }^{12} \mathrm{H}$ Príncipe Asturias, Madrid, Spain; ${ }^{13} \mathrm{H}$ Donosti, San Sebastián, Spain; ${ }^{14} \mathrm{H}$ Virgen Arrixaca, Murcia, Spain; ${ }^{15} \mathrm{H}$ Salamanca, Salamanca, Spain; ${ }^{16} \mathrm{H}$ Marina Baixa, Villajoyosa, Spain; ${ }^{17} \mathrm{H}$ Marqués Valdecilla, Santander, Spain; ${ }^{18} \mathrm{H}$ Orense, Orense, Spain; ${ }^{19} \mathrm{HG}$ Alicante, Alicante, Spain; ${ }^{20} \mathrm{H}$ Ramón y Cajal, Madrid, Spain; ${ }^{21} \mathrm{H}$ Bellvitge, Hospitalet, Spain; ${ }^{22} \mathrm{H}$ Virgen Macarena, Sevilla, Spain; ${ }^{23} \mathrm{H}$ Puerta Hierro, Madrid, Spain; ${ }^{24} \mathrm{H}$ Insular, Las Palmas Gran Canaria, Spain; ${ }^{25} \mathrm{H}$ Canarias, Tenerife, Spain; ${ }^{26} \mathrm{H}$ Jerez Frontera, Jerez, Spain; ${ }^{27} \mathrm{H}$ Son Llátzer, Palma de Mallorca, Spain; ${ }^{28} \mathrm{H}$ Santa Creu i San Pau, Barcelona, Spain; ${ }^{29} \mathrm{H}$ Parc Taulí, Sabadell, Spain; ${ }^{30} \mathrm{H}$ San Cecilio, Granada, Spain $;{ }^{31} \mathrm{H}$ Monforte, Monforte, Spain; ${ }^{32}$ H Lugo, Lugo, Spain; ${ }^{33} \mathrm{H}$ Povisa, Vigo, Spain; ${ }^{34} \mathrm{H}$ Meixoeiro, Vigo, Spain

Background: The mortality in Systemic Lupus Erythematosus (SLE) varies largely across different countries most probably due to social, healthcare and ethnic differences.

Objectives: To analyze the causes and identify predictive factors of mortality of SLE in Spain in the present century.

Methods: We performed a cross-sectional and retrospective study analyzing data from the RELESSER cohort (Spanish Registry of Systemic Lupus Erythematosus of the Spanish Society of Rheumatology). We included all patients diagnosed with SLE since the year 2000 and recorded sociodemographic, clinical and serological variables, comorbidities and treatments, as well as indicators of disease activity, damage and severity. The characteristics of the deceased patients were compared with those of the survivors, and variables with clinical significance or statistical significance were grouped into multivariate models to determine which ones were independently associated with the outcome of the disease.

Results: A total of 2004 patients were included, $88.6 \%$ female, the mean age at diagnosis was $38.3( \pm 15.3)$ years, with a mean delay in diagnosis of $28.9( \pm 52.6)$ months. Up to $2.84 \%$ of the individuals had died. The leading cause of death was SLE activity $(n=16)$, followed by infections $(n=14)$, vascular events $(n=7)$ and can$\operatorname{cer}(n=6)$. The mean age of death was $54.68( \pm 20.13)$ years, and neither age, sex nor delay in diagnosis was independently associated with mortality. The presence of nephritis, depression, severe infections, organ damage (SLICC/ACR DI) or disease activity (SLEDAI), as well as the use of cyclophosphamide, rituximab or high doses of corticosteroids, were predictors of mortality in our cohort. Antimalarial treatment and skin manifestations were linked to improved survival.

Conclusion: In the RELESSER cohort, clinical factors, co-morbidities, as well as therapeutic attitudes were associated with a significant increase in mortality in SLE. Interestingly, depression was independently associated to mortality. The activity of the disease and infections continue to be the main causes of death at the beginning of the 21 st century amongst our patients. 
Disclosure of Interests: Clara Moriano: None declared, Jaime Calvo Grant/ research support from: Lilly, UCB, Consultant of: Abbvie, Jansen, Celgene, Iñigo RuaFigueroa: None declared, Elvira Diez Alvarez: None declared, Cristina Bermúdez: None declared, Francisco J López-Longo Grant/research support from: AbbVie and GSK, Speakers bureau: AbbVie, Actelion, Bristol Myers Squibb, GSK, MSD, Pfizer, Roche, and UCB Pharma, María Galindo-Izquierdo: None declared, Alejandro Olive: None declared, Eva Tomero Muriel: None declared, Antonio Fernandez-Nebro: None declared, Mercedes Freire González: None declared, Olaia Fernández- Berrizbeitia: None declared, Ana Pérez Gómez: None declared, Esther Uriarte Isacelaya: None declared, Carlos Marras Fernandez Cid: None declared, Carlos A. Montilla-Morales: None declared, Gregorio Santos Soler: None declared, Ricardo Blanco Grant/ research support from: AbbVie, MSD, and Roche, Speakers bureau: AbbVie, Pfizer, Roche, Bristol-Myers, Janssen, and MSD, M. Rodíguez-Gómez: None declared, Paloma Vela-Casasempere: None declared, Alina Boteanu: None declared, J. Narváez: None declared, Victor Martinez Taboada: None declared, Blanca Hernández-Cruz Speakers bureau: Abbvie, Lilly, Sanofi, BMS, STADA, José Luis Andreu: None declared, José A Hernandez Beriain: None declared, Lorena Expósito: None declared, Raúl Menor-Almagro: None declared, Mónica Ibañez Barceló: None declared, Ivan Castellví Consultant of: Boehringer Ingelheim, Actelion, Kern Pharma, Speakers bureau: Boehringer Ingelheim, Actelion, Bristol-Myers Squibb, Roche, Carles Galisteo: None declared, Enrique Raya: None declared, Víctor Quevedo Vila: None declared, Tomas Vazquez Rodriguez: None declared, Jesus Ibañez: None declared, Jose M Pego-Reigosa: None declared

DOI: 10.1136/annrheumdis-2020-eular.5035

\section{SAT0222 \\ CLINICAL SPECTRUM AND LONG TERM FOLLOWUP OF SYSTEMIC LUPUS ERYTHEMATOSUS-ASSOCIATED MACROPHAGE ACTIVATION SYNDROME}

T. Okano $^{1,2}$, J. Saegusa ${ }^{1,2}$, K. Yoneda ${ }^{2}$, I. Shirasugi ${ }^{2}$, Y. Ueda ${ }^{2}$, K. Akashi ${ }^{2}$, A. Onishi ${ }^{2}$, A. Morinobu ${ }^{2} .{ }^{1}$ Kobe University Hospital, Clinical Laboratory, Kobe, Japan; ${ }^{2}$ Kobe University Hospital, Rheumatology and Clinical Immunology, Kobe, Japan

Background: Systemic lupus erythematosus (SLE) patients present with variable clinical features ranging from mild joint and skin involvement to life-threatening organ involvement such as nephritis, neuropsychiatric involvement, diffuse alveolar hemorrhage, and hemophagocytic lymphohistiocytosis $(\mathrm{HLH})$. HLH is rare, but fatal complication of SLE. Recently, European League Against Rheumatism, the American College of Rheumatology, and the Pediatric Rheumatology International Trials Organization was to develop a set of classification criteria for MAS complicating systemic juvenile idiopathic arthritis (PRINTO criteria) [1]. Sung Soo Ahn and his colleagues reported PRINTO criteria predicted mortality of adult SLE patient, but they followed only one year [2].

Objectives: To reveal association PRINTO criteria with long term mortalities in SLE patient in our Hospital.

Methods: We performed a retrospective analysis of SLE patients who received moderate dose glucocorticoid therapy $(>0.4 \mathrm{mg} / \mathrm{kg} / \mathrm{d})$ in our hospital between April 2008 and April 2019. Patients were evaluated for HLH using the 2016 PRINTO

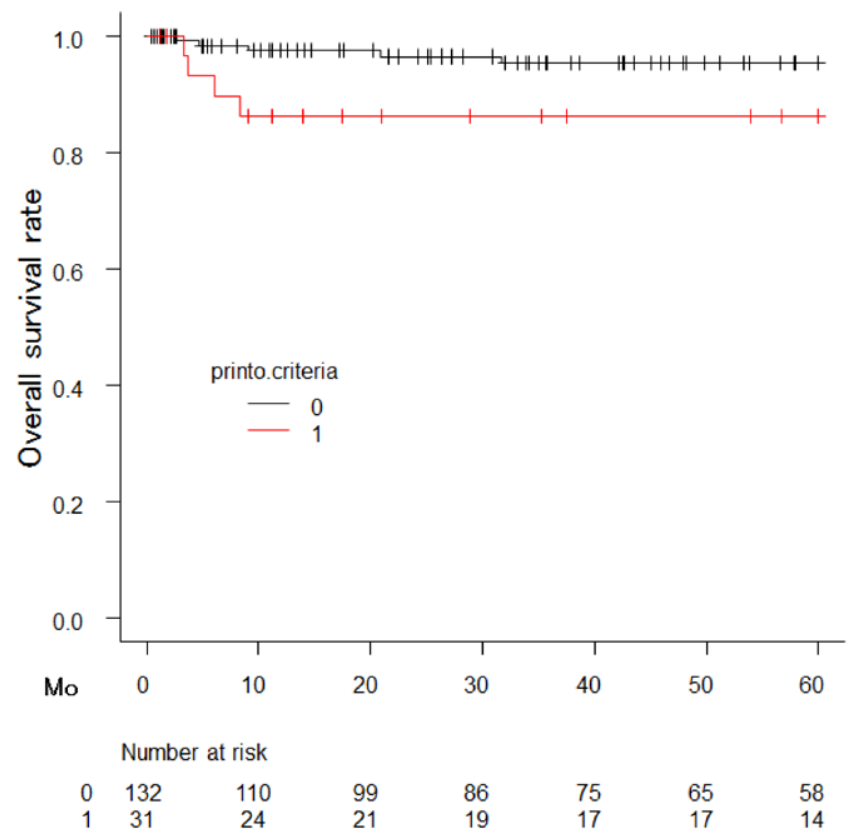

classification criteria for MAS. Clinical features and laboratory findings were compared and overall survival rate was analyzed.

Results: Among 164 episode (144 patients) with SLE, 31 episode (31 patients) $5.2 \%$ were considered to have MAS on admission.

The overall survival rate was significantly lower in patients with MAS than without MAS (86.2\% vs. 95.3\%, $p=0.048)$. Interestingly, SLEDAI had no association with mortality, relapse rate, and MAS complication. SLEDAI more focused on renal and neuropsychiatric symptoms than hematologic features. So SLEDAI might not be associated with MAS secondary to SLE. Furthermore, we observed no death patient with MAS after one year, and only 1 case relapse in MAS patient. So MAS might have fatal but less relapsing property compared with other lupus cases. Conclusion: PRINTO criteria may be useful to differentiated fatal MAS patients from others. Further investigations are required to confirm our findings. Limitation : The main limitations of our study include its retrospective design, single center site, and that the number of admitted patients with SLE was small.

Limitation: The main limitations of our study include its retrospective design, single center site, and that the number of admitted patients with SLE was small. findings.

Limitation : The main limitations of our study include its retrospective design, single center site, and that the number of admitted patients with SLE was small. References:

[1] Wulffraat N, Schneider R, Filipovic L, et al. 2016 Classification Criteria for Macrophage Activation Syndrome Complicating Systemic Juvenile Idiopathic Arthritis. Ann Rheum Dis 2016;75:481-9.

[2] Ahn SS, Yoo BW, Jung SM, et al. In-hospital mortality in febrile lupus patients based on 2016 EULAR/ACR/PRINTO classification criteria for macrophage activation syndrome. Semin Arthritis Rheum 2017;47:216-21.

Disclosure of Interests: None declared

DOI: 10.1136/annrheumdis-2020-eular.5135

\section{SAT0223 NEPHRITIS}

V. A. Pacucci ${ }^{1}$, F. R. Spinelli ${ }^{1}$, K. Giannakakis ${ }^{2}$, S. Colafrancesco ${ }^{1}$, S. Truglia ${ }^{1}$ F. Ceccarelli ${ }^{1}$, C. Garufi ${ }^{1}$, C. Alessandri ${ }^{1}$, F. Conti ${ }^{1}$ on behalf of Lupus Clinic Sapienza University of Rome. ' Sapienza University of Rome, Clinical, Internal, Anaesthesiologic and Cardiovascular Sciences - Rheumatology Unit, Roma, Italy; ${ }^{2}$ Sapienza University of Rome, Radiologic, Oncologic, and Pathologic Sciences - Pathology Unit, Roma, Italy

Background: Lupus nephritis (LN) occurs in up to $60 \%$ of patients affected by Systemic Lupus Erythematosus (SLE). The presence of inflammatory infiltrates in glomeruli and/or in tubulo-interstitium (TI) plays an important role in terms of prognosis (1). Ectopic lymphoid structures (ELSs) are clusters of organized lymphoid infiltrates forming at sites of chronic inflammation in non-lymphoid organs (2). Data on ELSs in kidneys of SLE patients are scant (3-5).

Objectives: The aim of the study was to evaluate the tubule-interstitial infiltrates (TI-I) organization and to investigate the presence of ELSs.

Methods: Kidney sections of SLE patients undergoing a renal biopsy for diagnostic purpose were studied; LN was diagnosed according to the 2003 International Society of Nephrology / Renal Pathology Society classification criteria. Clinical, laboratory and histological data were collected in a standardized, computerized and electronically filled form, including past medical history. The presence of lymphoid aggregates and ELS in the kidney sections were firstly evaluated by hematoxylin-eosin ( $\mathrm{HE})$. By using immunohistochemistry (IHC), we characterized the infiltrates by identification of T cells (CD3), B cells (CD20) and follicular dendritic cells (CD21).

Results: By HE we evaluated 53 kidney samples from $L N$ patients ( $F: M=51: 2$, mean age at biopsy \pm SD years $35 \pm 7.7$; mean disease duration at date of biopsy \pm SD $8 \pm 8.3$ years). $\mathrm{TI}-\mathrm{I}$ were found in 33 kidney specimens. By $\mathrm{HE}$ we identified a well-defined infiltrate pattern resembling ELS in 13 renal samples. In these samples, we confirmed the presence of organized infiltrates by $\mathrm{IHC}$, with evidence of segregated $T$ and $B$ cells areas in most of them. In one sample, the CD21 staining was positive confirming the presence of ELS (Figure 1). Interestingly, this last patient, who failed ciclophosphamide and mycofenolate, responded to rituximab administration and is now in complete LN remission. Moreover TII was negatively correlated with renal remission after induction therapy $(P=0.03)$ independent of the histological class and the induction treatment. 